The influence of macrocultural change on national governing bodies in British olympic sports

Niels B. Feddersen, Research Institute for Sport and Exercise Science, Liverpool John Moores University, Liverpool, UK

Robert Morris, Research Institute for Sport and Exercise Science, Liverpool John Moores University, Liverpool, UK

Frank E. Abrahamsen, Norwegian School of Sport Science, Oslo, Norway

Martin A Littlewood, Research Institute for Sport and Exercise Science, Liverpool John Moores University, Liverpool, UK

David J Richardson, Research Institute for Sport and Exercise Science, Liverpool John Moores University, Liverpool, UK

This is an Accepted Manuscript of an article published by Taylor \& Francis Group in Sport in Society on 18 May 2020, available online:

http://www.tandfonline.com/10.1080/17430437.2020.1771306 


\section{The Influence of Macrocultural Change on National Governing Bodies in British 2 Olympic Sports}

The study objective was to examine the temporal macrocultural changes in 
The Influence of Macrocultural Change on National Governing Bodies in British Olympic

Sports

Researchers have requested a 'widening of the lens' beyond the athlete to unpack

the context that influences processes and events (Schinke and Stambulova 2017). Two

broad lines of research have evolved as a consequence of mounting interest: (1)

organisational psychology, which involves identifying and fostering successful

organisational cultures, and (2) cultural sport psychology, which emphasizes understanding

cultural identities and the meanings that people assign to sports. Both underscore the

importance of attending to local surroundings to reveal cultural standpoints (Ryba et al.

2013; Schinke and Stambulova 2017). Although discussions have taken place on these

aspects, it is yet to be determined how the individual and the environment merge (Schinke and Stambulova 2017).

Thus, there is limited understanding of how environments are viewed within a

macrocultural context (i.e., encompassing interorganisational, local or national cultures). A

33 growing number of studies (Henriksen, Stambulova, and Roessler 2010; Storm et al. 2014;

34 Skille and Chroni 2018) and recent reviews (Wagstaff and Burton-Wylie 2018; Maitland,

35 Hills, and Rhind 2015; Blodgett et al. 2015) have attempted to consider the context.

36 Nevertheless, most of this research only briefly alludes to the idea that the environment or

37 the organisation might be embedded within a broader national culture.

Another significant limitation of the current research in organisational culture is that most studies view it using an integration paradigm (Meyerson and Martin 1987; Schein 1990), according to which organisational culture is perceived as a consensus-based closed

41 system in which each organisation exists in oblivion (Maitland, Hills, and Rhind 2015).

42 Meyerson and Martin (1987, p. 625) identified three common characteristics inherent to 
43 this line of research: 'consistency across cultural manifestations, the consensus among

44 cultural members - and usually — a focus on leaders as culture creators'.

45 However, utilising a singular characteristic to describe a group tends to detract from

46 a substantial amount of profound cultural understanding (Ryba et al. 2013). Only a few

47 studies (Skille and Chroni 2018; Telseth and Halldorsson 2019) have substantially

48 considered the macrocultural context. Skille and Chroni (2018) evaluated the organisational

49 cultures of Norwegian sports federations to understand how Norway amalgamates the

50 demands of elite sports with a balance-oriented national culture. Telseth and Halldorsson

51 (2019) approach macroculture as a form of cultural production, situated in its socio-

52 cultural, organisational and historical context. As what is understood about culture depends

53 directly on the conceptualisation of culture, culture is generally understood to be a

54 relatively closed system of consistency and consensus, which does not fully elucidate how

55 culture is constituted (Meyerson and Martin 1987; Stambulova and Ryba 2013).

56 An examination of values is the usual approach in cultural studies; however, this

57 prevents insight into the complexity of how values are enacted or formed (Maitland, Hills,

58 and Rhind 2015). Therefore, it is essential to gain insight into how cultures are formed and

59 enacted. Doing so includes paying attention to how cultures change and fluctuate. The

60 development of a best-practice approach to cultural change in sport has been retrospectively

61 sought in grounded theories of culture change in Olympic sport (Cruickshank, Collins, and

62 Minten 2014) and professional sport (Cruickshank, Collins, and Minten 2015). However,

63 limitations to these approaches include poor recall, hindsight, and self-preservation bias. In

64 addition, both these studies were limited in that they conceptualised culture change as a

65 leader-led approach without including stakeholders from any of the identified subunits.

66 Moreover, the influence of changes at the macrocultural level, and how these changes 
67 influence adaptive changes in sports organisations, such as national governing bodies

68 (NGBs), has not been evaluated in any study to date. Future research should encompass

69 emic real-time strategies, such as ethnography, to overcome these barriers and expand the

70 significance of culture (Schinke et al. 2018; Cruickshank, Collins, and Minten 2014;

71 Maitland, Hills, and Rhind 2015). With this in mind, the present study attempted to

72 evaluate a previously neglected area of cultural research and remove the traditional barriers

73 between researchers and participants.

74 Organisational culture framework

75 The present study forms part of a more extensive longitudinal study on culture

76 change in Olympic sports in the United Kingdom (see Feddersen et al. 2019). Following

77 Mannion and Davies (2016), we treat culture as "a root metaphor, simply something that an

78 organization is" (p. 98). This view allows us to focus on cultural dynamics and changes

79 over time. Meyerson and Martin (1987) presents three perspectives on culture: integration,

80 differentiation, and fragmentation. Our position in the present study is within the

81 differentiation perspective (Meyerson and Martin 1987). Yet, it is not within the scope of

82 this article to discuss the three. Instead, we sign-post to Meyerson and Martin (1987) and

83 Martin (2002) for a thorough overview.

84 In the differentiation perspective, a culture is a boundary around a set of

85 subcultures. Subcultures are distinctly different and can exist in peaceful co-existence (i.e.,

86 orthogonal subcultures) counter to (i.e., counter subcultures) or supportive of (i.e.,

87 enhancing subcultures) other subcultures (Mannion and Davies 2016). Meyerson and

88 Martin (1987) explain that the differentiation paradigm allows a researcher to approach a

89 culture with the understanding that culture saturates everything and organisations are 
90 embedded in an open system. This recognition increases the saliency of diffuse and

91 unintentional sources of change, which raises the prospect that culture moves with events,

92 emphasising fluctuations in content and connections between subcultures (Meyerson and

93 Martin 1987).

94 In an open system, unanticipated changes outside an NGB can have widespread

95 consequences for the composition of subcultures if these changes mandate adaptation

96 (Meyerson and Martin 1987). Macroculture might, therefore, be the changes that occur

97 outside an NGB, which might reflect broader societal cultures that contain occupational,

98 hierarchical, class, racial, ethnic and gender-based identification (Meyerson and Martin

99 1987). For the present study, we draw on Meyerson and Martin (1987) and Rosa and Tudge

100 (2013). Accordingly, we treat macrocultural change as changing patterns of beliefs,

101 resources, and hazards, as well as changing expectations and events in society, both within

102 and across generations, within a larger context.

103 The current study gave consideration to the fact that only a few large, complex

104 organisations are characterised by an unambiguous culture (Mannion and Davies 2016). For

105 the sake of clarity, sports organisations were viewed as co-existing subcultures that are

106 loosely coupled with one another (Meyerson and Martin 1987). This coupling can buffer

107 responses to change wherein inconsistencies arise in the way in which governing sports

108 organisations and NGBs experiment and respond (Meyerson and Martin 1987). Thus, the

109 study objective was to examine the temporal macrocultural changes in Olympic sports in

110 the United Kingdom and what regulates these changes.

\section{Methodology}

112 In adopting an open-system perspective on culture, an attempt was made to look outwards

113 to notable changes that occurred outside NGBs in Olympic sports in the United Kingdom. 
114 The combined use of action research and grounded theory were applied to the participatory

115 inquiry paradigm to consider both change and the process behind it (Dick 2007; Redman-

116 MacLaren and Mills 2015; Heron and Reason 2006). In adopting a participative axiology,

117 efforts were focused on bringing together areas that were most meaningful to the

118 participants.

119 The context of Olympic sports organisations in the United Kingdom

1202004 marked the beginning of the 'No Compromise' framework in Olympic sports in the

121 United Kingdom (UK Sport 2004). UK Sports stated that the new approach would:

122 'strengthen the best, support the developing and provoke change in the underperforming'

123 (UK Sport 2004). Yet, multiple investigations (cf. King 2012; Phelps et al. 2017; Grey-

124 Thompson 2017) into the elite sports practices shed light on the possible adverse effects of

125 this 'No Compromise' approach. Phelps, Kelly, Lancaster, Mehrzad, and Panter (2017)

126 suggested in their report on the World Class Programme (WCP) in British Cycling that:

127 "No Compromise" has, within the WCP, also come to reflect the single-minded pursuit of

128 medal-targets in order to retain funding rather than promptly addressing behavioural issues

129 within the WCP (p. 52). The adverse examples were argued to put the sport sector 'under

130 more scrutiny than ever before' (Grey-Thompson 2017, 4).

\section{$131 \quad$ Procedure}

132 A longitudinal study design was selected, and the study commenced in July 2017 after

133 ethical clearance was obtained from the Liverpool John Moores University's ethics board.

134 The starting point of the study was an NGB (hereinafter referred to as 'NGB-1') based on

135 post-2016 Olympic Games funding changes. NGB-1 is anonymised due to findings

136 concerning adverse behaviours (Feddersen et al. 2019). It is a long-standing part of the 
137 Olympic Summer Games with approximately 15000 members who carry out the sport in

138 clubs and with personal coaches. Specifically, the perspective of a research group labelled

139 the 'talent team' (comprising the talent manager; head of coach development; talent

140 administrator, assistant talent manager, Great Britain head talent coach and the first author)

141 was evaluated. Although the NBG-1 members in the research group were primarily were

142 responsible for the talent pathway, they also oversaw the senior elite programme, as well as

143 coach, leader, and referee development. Consequently, they were responsible for the entire

144 performance pathway.

145 An attempt was made to understand the prevailing NGB-1 context during the 146 reconnaissance phase (July to November 2017) and to also served to identify anomalies 147 through theoretical sampling (Weed 2017). It became evident that NGB-1 did not exist in 148 oblivion but changed as distal levels influenced the inside conditions for culture change.

149 Findings from the reconnaissance phase led to the purpose and the focus of this article to

150 examine the macrocultural changes that were perceived to occur outside NGB-1.

151 Consequently, information on the prevailing context was juxtaposed with data on

152 macrocultural conditions using four double cycles (Gilbourne and Richardson 2005) of 153 implementation and monitoring, and reflection and review.

154 The data collection phase was concluded when consensus that theoretical saturation

155 had occurred was reached. As a part of this process, the first author carried out two focus

156 group discussions with the parents of the athletes, one focus group discussion with the

157 talent team and three individual interviews with the talent manager, coach development

158 manager and the NGB-1 CEO. This process was terminated with a meeting in November

1592018 with two NGB participants and one participant from a Governing Sports Organisation

160 (GSO) to assess the theoretical fit (Weed 2017; Heron and Reason 2006). The significance 
161 of this meeting was that a broader range of participants could be included in the process of

162 terminating the research by assessing its fit, work, relevance and modifiability (cf. Weed,

163 2017) in other contexts. In the light of the 2017 government-funded report on the duty of

164 care in Olympic sports (viz., Grey-Thompson, 2017) and the current focus of these three

165 organisations, the consensus was that the findings reflected the real-world concerns of

166 athletes working in sport and those employed in present-day sports institutions. The first

167 author terminated his direct engagement with the NGB-1 in November 2018 after

168 consensus was reached that theoretical saturation had occurred.

169 Participants

170 To understand the prevailing context in relation to the NGB-1, an initial sample of NGB-1

171 personnel was recruited ( $n=4$; one of whom was a woman). This group identified three other 172 important stakeholder groups; athletes aged 18-23 years $(n=15$; eight of whom were 173 women), coaches ( $n=10$; one of whom was a woman) and parents $(n=10$; six of whom 174 were women). The findings from these four groups led to the recruitment of a subsequent 175 sample within the focal sport using theoretical sampling (Weed, 2017). This sample consisted 176 of parents of athletes in underserved areas $(n=2)$ and members of counter subcultures $(n=$ $1771)$.

178 The key focus of the present research was on the nine individuals identified via 179 subsequent theoretical sampling from other NGBs and GSOs (Table 1).

180 [Please place Table 1 near here]

181 The intention was to identify individuals who represented either British or home-

182 country governing bodies, NGBs in charge of both the talent pathway and participation,

183 NGBs who were solely responsible for a performance pathway, as well as personnel

184 representing GSOs and other relevant sports organisations. 
The identified talent leads represented three different NGBs: NGB-A was a single-

186 event sport organised by a governing body which was exclusively in charge of talent

187 development and senior elite athletes. NGB-B was a multi-event home-country governing

188 body in charge of grassroots sport and competitions, and that collaborated with the Great

189 Britain governing body on coach development, talent development and senior elite

190 performance. Lastly, NGB-C was a multi-event Great Britain governing body in charge of

191 membership, grassroots sports, coach development, talent development and senior elite

192 performance. The experience of the talent leads in their current position ranged from less

193 than one year to six years. The collaborative approach also helped to identify six GSOs (i.e.,

194 UK Sport, Sport England, the English Institute of Sport, UK Coaching, the Talented Athlete

195 Scholarship Scheme and a university sports programme) of interest. All of the participants 196 were anonymous.

\section{Data Collection Strategies}

198 Having considered the recommendations made by Maitland et al. (2015), a decision was

199 made to adopt emic data collection strategies to examine the ebb and flow of the culture

200 change process. It was necessary to bring collaboration and democratic dialogue to the

201 forefront of the study as a consequence of the use of participative epistemology (Heron and

202 Reason 2006). Ethnographic observations were used as the primary method of assessing

203 interrelationships within the change process to obtain a meaningful description of events as

204 they unfolded (Krane and Baird 2005).

205 The first author was stationed at NGB-1 as a part of the talent team for 16 months

206 and carried out extensive fieldwork to evaluate departmental, interdepartmental and

207 organisational meetings and events at the offices of NGB-1, national youth team camps,

208 coach development courses, competitions, public events and staff outings. The role of the 
209 first author was to assume the role of a 'critical friend' (cf. Costa and Kallick 1993; Chroni

210 et al. 2019). Extensive field notes were recorded using core grounded theory elements (i.e.,

211 memorandums and diagrams), with a focus on action strategy and change process outcomes

212 (Baskerville and Pries-Heje 1999; Holt 2016).

213 The first author carried out ten focus group discussions that lasted between 40 and

214130 minutes on average, with a view to understanding the organisational culture in a

215 broader sense. The focus group discussions served two main purposes; firstly, to provide a

216 purposeful forum through which participants could engage in democratic dialogue, and

217 secondly, to raise sensitivity to interpersonal communications and meaning-making by

218 highlighting subcultural understandings of the change process and making the group

219 interactions the explicit focus (Kitzinger 1995). The focus groups were divided into defined

220 groups (i.e., a talent team, parents of the athletes, coaches and athletes) to analyse

221 individual and collective perceptions and evaluate the intra-group subcultural processes of

222 dialogue and negotiation.

223 As mentioned previously, the area of interest in this research was the data elicited

224 through individual interviews, although these were meaningless if treated as stand-alone

225 information. Twenty-six individual semi-structured interviews were conducted, with an

226 average duration of 37-75 minutes. Eighteen of these were with the main interest group

227 (see Table 1), as described previously (Brinkmann and Kvale 2018). The individual

228 participants were interviewed twice, during spring and winter in 2018, via Skype to

229 accommodate their busy schedules and geographical constraints (Janghorban, Roudsari,

230 and Taghipour 2014). The interview guide used for the first interviews covered the

231 objective of talent development, changes to the talent pathway, societal influences on talent

232 development and linkages to other sports organisations. The interview guide for the follow- 
233 up interviews aimed to provide more contextual depth and considered the iterative findings

234 of how the culture had changed, as well as the findings from the first round of interviews

235 (Culver 2012; Smith and McGannon 2018).

236 Lastly, documents and web pages were obtained to provide greater contextual depth

237 to NGB-1 and the community of the sport. These documents included training programmes,

238 official papers describing the mission, organisational structure and public communication

239 documents.

240 Analysis and Rigour

241 As suggested by Holt and Tamminen (2010), open coding commenced immediately after

242 the first data collection in the reconnaissance phase, and this coding was considered to be

243 the starting point of iterative analysis. The implementation and review phase involved open

244 coding to encourage novel ideas and help prevent early foreclosure (cf. Corbin and Strauss

245 2015). The reflection and review phase entailed conceptualising the influence of

246 macroculture on the process of culture change. Memorandum writing, as well as

247 introducing the conditional/consequential matrix and paradigm from Corbin and Strauss

248 (2015), aided the transition from open coding during the implementation and review phase

249 to conceptualisation during the reflection and review phases.

250 In keeping with the participative approach, the first author presented the findings

251 regularly at talent team meetings to engage its members in iterative analysis. This enables

252 members of the team to feel part of the process and trusted to draw out what is intrinsically

253 worthwhile (Heron and Reason 1997).

254 Rigour in this study was achieved through collaborative inquiries used to enrich

255 understanding through dialogue, in conjunction with the application of all core grounded

256 theory elements (Smith and McGannon 2018). Conducting a comparison of the ways in 
which the co-researchers understood the concepts and interpreted the data helped to ensure analytical diversity. The immersion and collaboration within the Talent Team opened up unique nuances and insights.

260 Results

261 In this section, the prevailing context (and channels through which society and GSOs might

262 influence culture change) is outlined. Secondly, consideration is given to how societal

263 changes influence the connection between NGBs and GSOs and to the perceived influence

264 of these changes on cultural change. The ways in which these findings contribute to an

265 understanding of culture change in NGB-1 are then described.

\section{The Influence of Outside Structural Conditions on a Change of Culture}

267 We found that it was crucial to understand the ability of the macrocultural landscape to 268 influence adaptive changes within Olympic sports. The model applied consisted of four

269 embedded levels of structural conditions outside and inside NGB-1, three of which 270 comprised Outside Structural Conditions (Figure 1). The three levels included the societal

271 level comprised of systems of changing societal norms, values and beliefs, as well as social,

272 physical, educational and political systems. The next level, the GSO level, included sports

273 organisations that work within Olympic sports in the United Kingdom and influence NGBs.

274 The third level, the NGB level, was made up of NGBs in Olympic sports. The last level 275 covered Inside Structural Conditions and described the properties of an individual NGB 276 and subcultures within a sport.

277 [Please place Figure 1 near here]

278 Coupling of organisations and layers was demonstrated to be an evolving system of 279 dependency that included horizontal dependency (i.e., the degree to which same-level 280 organisations were dependent on one another) and vertical dependency (e.g., the degree of 
281 dependence between organisations situated in the GSO and NGB layers). Generally,

282 coupling denotes the extent to which individual organisations are dependent on other

283 organisations to function and influence adaptive changes. At the outset of the current study,

284 the analysis indicated that GSOs and NGBs in Olympic sports were primarily protected

285 from societal level influences (denoted by the solid ring in Figure 1). This protection

286 buffered the need for responsive changes. GSO personnel and pathway managers agreed

287 that societal changes had little adverse influence on cultural change within Olympic sports

288 (Figure 1). Instead, most Olympic sports enjoyed sizeable public support and political,

289 which meant that they were able to capitalise on the traditions and working practices

290 needed to ensure cultural continuity.

291 Within this interorganisational structure, participants suggested that personnel

292 engaged with personnel at other NGBs or GSOs at continued professional development

293 opportunities and through other forums. However, participants also reported that these

294 interactions had little influence on changes within their own organisation. In particular,

295 NGBs had little horizontal interdependence, and the pathway managers reported a sense of

296 loose coupling (Figure 1). When asked about an NGBs collaboration with other NGBs a

297 pathway manager of an England NGB mentioned: '[Us] not so much. I mean [GB

298 organisation of NGB-C] obviously .. and EIS' (NGB-C). Structural conditions that

299 influenced loose coupling included demanding day-to-day operations, and perceptions of

300 interorganisational incompatibility (i.e., working practices, approaches to coaching and

301 sport-related differences). This perceived incompatibility amounted to NGBs not perceiving

302 other NGBs to have the legitimate power to influence changes.

303 The vertical structure placed NGBs as a conduit between a GSO and their respective

304 communities within their sport. The vertical dependency was generally structured as a 
relationship between GSOs and NGBs, and the NGB and its sports community. The link

306 between the Outside and Inside Structural Conditions is represented by two channels

307 (Figure 1). These represent direct dependency between NGB-1 and GSO levels, thereby

308 facilitating the indirect transfer of knowledge; first from other NGBs to the GSO level, and

309 secondly from the GSO level to NGB-1. Limited horizontal and vertical coupling led to

310 localised changes and inertia with respect to making adaptive changes.

311 Importantly, varying perceptions of the systemic power of a GSO influenced its link

312 to an NGB. The pathway managers agreed that their relationship with Sport England and UK

313 Sport mainly revolved around funding: 'To be honest, yes. I think they would like to see it

314 not be that and so would we in some ways. But it tends to just default back to that [funding]

315 position. (NGB-B). Pathway managers mentioned that Sport England and UK Sport had a

316 large degree of systemic power that they utilised to prescribe changes and drive the focus of

317 NGBs. This systemic power was seen to be partly linked to a coercive offer, wherein the

318 funding GSOs were able to rearrange the available options relating to the Inside Structural

319 Conditions of an NGB based on a perceived threat of a fragile and insecure funding

320 relationship: 'They are being pushed. You know, governing bodies are being pushed by UK

321 Coaching by Sport England ...to make sure they have these things in place and [to look] after

322 young people down that talent pathway' (Participant from a GSO).

323 GSOs influenced the Inside Structural Conditions pertaining to an NGB by dictating

324 conditions that warranted adaptive changes. These conditions included, but were not

325 limited to, funding conditions, updating normative coaching practices, safeguarding and

326 welfare changes, and strategic supervision of how the allocated funding was spent. A

327 vertically dependent relationship was particularly important owing to the perception of

328 having to be increasingly accountable to the funding bodies. 


\section{Ongoing Process of Coupling Macrocultural and Cultural Changes}

330 Consideration is now given to how changes influenced NGBs within Olympic sport. While

331 variations in localised changes are likely to exist different organisations, the pathway

332 managers and GSO personnel reported experiencing the macro changes that impacted

333 individual changes. When describing the period prior to the study (i.e., the Olympic cycles

334 leading up to London 2012 and Rio de Janeiro 2016), the stakeholders tended to refer to it

335 as a 'golden' sports period. The perception was that this period received significant support

336 and that this shielded GSOs and NGBs from the influence of societal events: 'We [Olympic

337 sports] have been through something of a golden period in every way in British sport down

338 to the lottery, but also, the political will that is behind that finance has been incredibly

339 supportive for sports' (NGB-B).

340 The positive consequence of this view was that Olympic sports enjoyed a

341 significant degree of autonomy without strategic supervision of how the funding was spent.

342 However, the consensus was that medals had to be produced continually in relation to

343 Olympic sports to maintain this level of independence. By contrast, this approach was also

344 associated with socially undesirable behaviour:

345 I think the pursuit of performance can often lead to people getting away

346 with cracking the whip. What has emerged over the past 12 to 18

347 months in various parts of British sports [is] the idea that trying to be

348 the best and win medals is often used as justification for behaviour that

349 in any other world would be seen as bullying or inappropriate.

$350 \quad$ (Participant from a GSO)

351 In this regard, the consensus between GSOs, NGBs, and stakeholders in sport (i.e.,

352 athletes and coaches) was formidable, highlighting that the organisational culture in sports 
353 at the time was increasingly deficient and required radical changes. This consensus

354 pertained to two interconnected changes: the emergence of social media (Societal level) and

355 a process leading to the emergence of the 'athlete's voice' (within Olympic sport). This

356 process involved an increasing number of NGBs focusing on the development of increased

357 athlete ownership regarding decision-making and own development:

‘..."We have got this really new idea, and it is a bit wacky"... What they would then say [is] "What we want to develop is athletes [having] ownership over their own things and [making] decisions themselves". And I would be like, "Yes, you and everyone else". (NGB-C).

enhanced athlete ownership; yet, a lack of horizontal connectivity meant that these changes

364 remained localised, exemplifying the overall inertia in making incremental changes.

365 Whereas Olympic sports had previously enjoyed considerable independence and less

366 scrutiny, the mounting 'athlete's voice" cut through and exposed catalysing events for less

367 desirable behaviours:

Then there [are] technological advances, probably related to social media, where the athlete's voice is huge now. So, you can't ignore the athlete's voice, whereas previously their forum for communicating was much smaller. So, I think it has changed so much in 10 or 20 years that

374 Talent leads and GSO personnel interpreted this as an increase in the legitimacy of the 375 athletes' message and informational power. The saliency of this coupling was evident in the interviews conducted, and observations made during the study. Participants viewed 
377 technology as a diffuse source of change. Athletes used their reinforced position by

378 speaking out about aspects that challenged the welfare of athletes and others working in

379 Olympic sports.

380 These catalysing events served as unanticipated sources of change in terms of public

381 exposure, which mandated changes. The influence of this process was that the normative

382 approach was under increased scrutiny in most sports: '...A number of times I have heard

383 coaches in a couple of other sports say [that] what was acceptable only ten years ago simply

384 isn't now' (NGB-C). This statement reveals that the exposure of incidents in sports led to

385 radical changes regarding the perceived legitimacy of certain behaviours.

386 The perceived economic fallout of exposure.

387 Participants thought that the changes to oversight in elite sports might be owing to 388 the advancement of new norms and standards regarding what was acceptable. The 389 participants mentioned that general legislation and regulation in sport was perceived as a long 390 and evolutionary process. However, participants agreed that the consequence of poor 391 behaviour and accounts of bullying catalysed increased regulation with respect to greater 392 strategic supervision in Olympic sports:

393 So, I sat in on the funding meeting leading into the new four-year cycle

394 from 2017 to 2021. I was representing [a national NGB]. There was

395 someone representing [a GB NGB] on the talent side. And we had a

396 meeting with Sport England. It has changed since then. But essentially,

397 the Sport England talent team and UK Sport talent team. Their strong

398 view was [that] public money [should] be accountable. Therefore,

399 [investment] should be systemised, and actually, if we systemise we can

400 measure better, and we can therefore be accountable for the return on 
investment. (NGB-B)

Financially, it was demonstrated that it would be in the interests of NGBs to change

403 their structure to that of a more professional organisation as this would then provide greater

404 strategic supervision of how the funding was spent. This finding was based on the

405 perception that public funding agencies, such as Sport England, are moving towards a more

406 directive funding model, where NGBs are rewarded for attentive regulation. It was apparent

407 that the NGB we evaluated in the present study made a considerable effort to satisfy the

408 interests of GSOs:

409 We didn't agree the targets until November of the first year, supporting other changes and this, that and the other. We hadn't recruited a team until then, end of November. You're playing catch-up whilst trying to start something new (NGB-1).

414 their changes challenged the existing organisational culture within the sport. These

415 challenges were met by antagonism from subcultures, which made it extremely difficult to

416 implement changes. In two seemingly opposing ways, GSOs pushed the NGBs to make

417 adaptive changes to funding conditions while simultaneously providing a set of armour to 418 mobilise the appropriate power capacity for change.

419 First, exhorting NGBs to make rapid adaptive adjustments, such as moving from a 420 position of independent volunteers to one in which they are subject to strategic oversight by 421 professionals could have resulted in a litigious process since the volunteers who were left 422 behind or who had to involuntarily cede power were some of the biggest causes of conflict. 423 Secondly, the GSOs stated that any prospective funding conditions and the financial 424 backing provided by them constituted power by proxy, meaning that the NGBs could have 
425 accessed the systemic power of funding bodies to drive and sustain changes within their

426 sport. However, limited efficacy associated with this support was identified since the

427 legitimacy of the GSO generally influenced the link to the NGB and, less so, a link to

428 individuals or subcultures within the sport being evaluated. Instead, the imposed changes

429 signified radical changes within the sport, leading to ambiguity and uncertainty for within-

430 sport stakeholders, and ultimately led to an uneasy symbiosis and tension between

431 divergent subcultures.

\section{Discussion}

433 This study provides empirical insight into how changes outside an organisation is perceived

434 to influence the organisational culture of sports organisations. That is, how macrocultural

435 changes are perceived by NGBs in British Olympic sport. We found that the conditions

436 outside NGBs included the Societal level, the GSO level, and the NGB level (see Figure 1).

437 The findings provided evidence of the influence of interorganisational coupling, which is

438 linked to an evolving system of horizontal (i.e. within levels) and vertical dependency (i.e.

439 across levels). The findings also have implications for research and applied practice within

440 elite sport organisations. Firstly, the results were ascertained by studying the processes

441 along the way rather than in retrospect, which suggests that the combined use of grounded

442 theory and action research methodologies was feasible. This approach provided insight into

443 how power shapes interorganisational linkages. Secondly, the study demonstrates that it is

444 important for practitioners to understand a given site, beyond its people, prior to conducting

445 an intervention. Thus, the findings call for a context-driven approach to research and

446 practice in culture change, sport psychology and talent development in sport.

447 This study constitutes a stimulating evolution of research, especially for grounded

448 theory purists. A significant criticism raised by researchers has been the deliberate selection 
449 of favourable grounded theory elements in sport and exercise (Holt and Tamminen 2010;

450 Weed 2017, 2009; Holt 2016). Disapproval pertains to the use by some researchers of only

451 a couple of elements, most notably coding techniques, and the consequential erroneous

452 labelling of the studies as grounded theory (Holt 2016). Also, Weed (2017) limits grounded

453 theory to three forms of epistemology; realist positivist, realist interpretivist and

454 constructivist interpretivist. This study evolved out of dissatisfaction with the approach

455 used by researchers in disregarding participants and viewing them as passive 'vessels' who

456 are incapable of making decisions for themselves (cf. Heron and Reason 2006). It was

457 against this backdrop that an attempt was made to push academic thinking further by

458 combining the grounded theory and action research methodologies using a participative

459 epistemology (Heron and Reason 1997). It was thought that this constituted considerably

460 more than a merger of two research designs; it was a study on how epistemology

461 completely underpins the expression of all core elements of both approaches in the

462 participatory inquiry paradigm. Holt (2016) argued that grounded theory is relevant when

463 there is a need to create a new theory to explain social phenomena, and that it was

464 particularly suited to research with a focus on changes in conditions. The strength of the

465 present study was that it thoroughly shaped the methodology and data collection strategies

466 using a coherent epistemology by drawing the participants into deeper engagement by

467 considering how diffuse and unexpected macrocultural changes link to culture change in an

468 Olympic sport.

469 A second finding of this study relates to the changing expression of culture, which

470 firmly challenges the prevailing vantage point of culture change in sport research

471 (Maitland, Hills, and Rhind 2015). This challenge rests on the research question and

472 methodology. Asking what culture is will generally produce an answer that involves a set 
473 of values, beliefs, working practices or basic assumptions that are dependent on a

474 theoretical framework. Using etic methodologies when conducting an inquiry involves the 475 danger that critical elements will be disregarded (Maitland, Hills, and Rhind 2015).

476 Evidence of this with respect to culture change includes research that argues that culture 477 change is reliant on the need to uphold shared values, standards and practices through 478 interactions with different stakeholders (Cruickshank et al., 2014, Cruickshank et al., 2015). 479 This is a functional perspective and, alongside work derived from Schein (1990), presents a 480 number of levers to leaders that they can use to carry out unproblematic culture change at 481 their discretion (Martin 2002; Maitland, Hills, and Rhind 2015). Nonetheless, this implies 482 stasis; how things are establishes how they will remain.

483 This study asks how is culture, which is in line with the definition of organisational 484 culture as a dynamic process. This definition conceptualises change by continuity, wherein 485 a culture adapts to changing conditions through an evolutionary process (Mannion and 486 Davies 2016). It also conceptualise changes as radical, wherein a culture responds to a 487 growing cultural deficiency or lag by overhauling the fundamental nature of the culture 488 (Mannion and Davies 2016). Both imply that the status quo is impossible since the process 489 of culture is fundamentally changing, either continuously or radically. Our findings support 490 the ongoing process; yet, it was also noted in the present research that some conditions and 491 interorganisational structures might be in place that serve to sustain a sense of status quo.

492 However, the findings suggest that this is a fallacy since the experienced status quo might 493 be cultural continuity.

494 When the question is posed of how this study connects to previous research, several 495 compelling connections were found. First, there is growing confidence in the assertion 496 made by Cruickshank, Collins and Minten $(2014,2015)$ that culture change is a dynamic 
497 process involving ongoing power that flows to and from stakeholders. The argument is that

498 the continuous flow of social power enables or hinders the change process. Yet, neither the

499 present study nor those carried out by Cruickshank, Collins and Minten $(2014,2015)$

500 delved into the properties of power.

501 Second, one of the key findings, with reference to power, pertained to the

502 interorganisational structure: the NGBs did not perceive other NGBs to have legitimate

503 power to influence change. However, Skille and Chroni (2018) found that several common

504 features existed in different federations in a Norwegian setting, and that organisational

505 closeness (i.e., being close to the competencies and expertise of other organisations)

506 characterised the success of these sports federations. When this is juxtaposed with the

507 present findings from four different NGBs, there is need for further research to consider the

508 extent to which different sports and their systems are genuinely different.

509 Third, the findings with reference to the 'athlete's voice' detail the process of

510 change as constituting a possible power asymmetry between the NGBs and athletes.

511 Mountjoy (2019) and the Ethics Centre (2018) both describe how the commodification of

512 athletes could be attributed to the development of destructive cultures. Yet, the process in

513 the UK indicated that the growing 'athlete's voice' could be a path to increased ownership

514 to cut through and expose catalysing events of less desirable behaviour. In addition,

515 growing power to athletes might also increase their capacity for action and enable radical

516 change by using their ability to unite (cf. Steen-Johnsen and Hanstad 2008).

517 Fourth, the findings on a shift from volunteerism to strategic oversight by

518 professionals represent an important consideration for sports organisations (Amis, Slack,

519 and Hinings 2004; Steen-Johnsen and Hanstad 2008; UK Sport 2019). Countries and NGBs

520 that rely on the voluntary sector for delivery (Skille and Chroni 2018; Bjørndal, Ronglan, 
521 and Andersen 2017; Bostock et al. 2018) might find that blurring the lines between

522 volunteers and professional staff could influence public policy-making through

523 repositioning, which could be particularly threatening to volunteer networks (Bostock et al.

524 2018). By contrast, NGBs might face growing concerns over the use of volunteers in the

525 decision-making process (cf. Amis, Slack, and Hinings 2004) since it could make an

526 organisation unwieldy or inefficient. Yet, as we have described, volunteers in sports

527 organisations or subcultures could make it litigious for an NGB to try to enforce change if

528 they have no intention to cede power (cf. Amis et al., 2004), especially as our findings

529 illuminated a possible linkage between GSOs and an NGB.

$530 \quad$ Future research should consider power struggles as elite sport organisations are

531 seemingly starting to shift to using professional staff. Attention in research should be

532 brought to how changes to funding conditions influence the context for culture change and

533 add to the findings by Amis, Slack, and Hinings (2004). Accordingly, the current study

534 finding is in support of their suggestion that although it might be financially relevant to

535 change, different interests could make this extremely difficult.

536 Strengths and Limitations of the Present Study

537 A limitation of the present study was the re-thinking of GT in the participative inquiry

538 paradigm. Weed $(2017,2009)$ asserted that researchers should adhere to established

539 paradigms. Yet, an example of how qualitative research is moving forward is consideration

540 of GT from a critical realist perspective (cf. Redman-Maclaren and Mills 2015) as this calls

541 for transformational GT. Redman-Maclaren and Mills (2015) highlighted a limitation of

542 their study, which resonates with the present study, namely that ongoing participation can

543 be challenging. They found that co-researchers were not always present for all iterations, 
544 yet, those who did participate often assumed leadership. Likewise, collaboration was not

545 found to be an unproblematic process in the present study; however, the talent team often

546 led the process of identifying avenues for theoretical sampling and provided profound

547 nuances of how they interpreted the influence of the societal level and GSOs. Accordingly,

548 Blodgett, Schinke, McGannon and Fisher (2015) suggest that engaging participants in the

549 reflexive process has implications that relate to understanding power and domination. And

550 in so doing, this could be useful when working towards decentralising the academic

551 researcher and bringing profound cultural insights to the forefront (Berger, 2005; Blodgett

552 et al., 2015).

553 Ultimately, based on the present study we conclude that the findings indicate that

554 organisational culture is not an attribute that can be manipulated at will. However, diffuse

555 sources of change might influence adaptive changes that sports organisations must adhere

556 to. Instead, we conclude that a change of culture process is influenced by conditions both

557 inside and outside an organisation. And not considering these structural conditions can have

558 significant influence on both GSOs and NGBs as they may experience a cultural deficiency

559 and lag possibly leading to conflict. The implications of these findings are also that sports

560 organisations should consider the vertical and horizontal coupling to other organisations or

561 subcultures, since the degree of coupling might influence the need for adaptive changes.

\section{References}

563 Amis, John, Trevor Slack, and C.R. Hinings. 2004. "Strategic Change and the Role of 564 Interests, Power, and Organizational Capacity.” Journal of Sport Management 18 (2): 565 158-98. https://doi.org/10.1123/jsm.18.2.158.

566 Baskerville, Richard, and Jan Pries-Heje. 1999. “Grounded Action Research: A Method for 
9 (1): 1-23. https://doi.org/10.1016/S0959-8022(98)00017-4.

569 Berger, Bruce. 2005. "Power Over, Power With, and Power to Relations: Critical Reflections on Public Relations, the Dominant Coalition, and Activism." Journal of Public Relations Research 17 (1): 5-28. https://doi.org/10.1207/s1532754xjprr1701.

\section{3}

Bjørndal, Christian Thue, Lars Tore Ronglan, and Svein S. Andersen. 2017. "Talent Development as an Ecology of Games: A Case Study of Norwegian Handball.” Sport, $\begin{array}{lllll}\text { Education } & \text { and } & \text { Society } & 22 & (7):\end{array}$ https://doi.org/10.1080/13573322.2015.1087398.

Blodgett, Amy T., Robert J. Schinke, Kerry R. McGannon, and Leslee A. Fisher. 2015. “Cultural Sport Psychology Research: Conceptions, Evolutions, and Forecasts." International Review of Sport and Exercise Psychology 8 (1): 24-43. https://doi.org/10.1080/1750984X.2014.942345.

Bostock, James, Phil Crowther, Rory Ridley-Duff, and Richard Breese. 2018. "No Plan B: The Achilles Heel of High Performance Sport Management." European Sport $\begin{array}{llll}\text { Management } & \text { Quarterly } & 18 & \text { 25-46. }\end{array}$ https://doi.org/10.1080/16184742.2017.1364553.

Brinkmann, Svend, and Steinar Kvale. 2018. Doing Interviews. 2nd ed. London: SAGE Publications Inc.

Chroni, Stiliani Ani, Frank Abrahamsen, Eivind Skille, and Liv Hemmestad. 2019. "Sport Federation Officials’ Practices and National Team Coaches' Stress.” International Sport Coaching Journal 6 (1): 63-73. https://doi.org/10.1123/iscj.2017-0086.

Corbin, Juliet M., and Anselm Strauss. 2015. Basics of Qualitative Research - Techniques and Procedures for Developing Grounded Theory. 4th ed. Thousand Oaks, CA: SAGE Publications Inc. 
MACROCULURE IN OLYMPIC SPORTS

592 Costa, Arthur L, and Bena Kallick. 1993. "Through the Lens of a Critical Friend." $593 \quad$ Educational Leadership 51: 49-51.

594 Cruickshank, Andrew, Dave Collins, and Sue Minten. 2014. "Driving and Sustaining Culture 595 Change in Olympic Sport Performance Teams: A First Exploration and Grounded 596 Theory." Journal of Sport \& Exercise Psychology 36: 107-20. 597 https://doi.org/10.1123/jsep.2013-0133.

598 Cruickshank, Andrew, Dave Collins, and Sue Minten. 2015. "Driving and Sustaining Culture 599 Change in Professional Sport Performance Teams: A Grounded Theory.” Psychology of $600 \quad$ Sport and Exercise 20: 40-50. https://doi.org/10.1016/j.psychsport.2015.04.007.

601 Culver, Diane M. 2012. "Qualitative Research in Sport Psychology Journals: The Next 602 Decade 2000-2009 and Beyond.” Sport Psychologist 26 (2): 261-81.

603 Dick, Bob. 2007. "What Can Grounded Theorists and Action Researchers Learn from Each 604 Other?" In The SAGE Handbook of Grounded Theory, edited by Antony Bryant and 605 Kathy Charmaz, 398-416. Thousand Oaks, CA: SAGE Publications Inc.

606 Feddersen, Niels B., Robert Morris, Martin A. Littlewood, and David J. Richardson. 2019. 607 "The Emergence and Perpetuation of a Destructive Culture in an Elite Sport in the 608

Gilbourne, David, and David Richardson. 2005. "A Practitioner-Focused Approach to the

611 Provision of Psychological Support in Soccer: Adopting Action Research Themes and 612 Processes." Journal of Sports Sciences $23 \quad$ (6): 651-58. 613 https://doi.org/10.1080/02640410400021344.

614 Grey-Thompson, Tanni. 2017. "Duty of Care in Sport Review." 2017. 615 https://www.gov.uk/government/uploads/system/uploads/attachment_data/file/610130 
/Duty_of_Care_Review_-_April_2017_2.pdf.

617 Henriksen, Kristoffer, Natalia Stambulova, and Kirsten Kaya Roessler. 2010. "Holistic Approach to Athletic Talent Development Environments: A Successful Sailing Milieu.”

Heron, John, and Peter Reason. 1997. “A Participatory Inquiry Paradigm.” Qualitative Inquiry 3 (3): 274-94.

623 Heron, John, and Peter Reason. 2006. "The Practice of Co-Operative Inquiry: Research 'With' People Rather than 'On' People.” In The Handbook of Action Research, edited

Holt, Nicholas L., and Katherine A. Tamminen. 2010. "Moving Forward with Grounded Theory in Sport and Exercise Psychology." Psychology of Sport and Exercise 11 (6):

Holt, Nicholas L. 2016. "Doing Grounded Theory in Sport and Exercise." In Routledge Handbook of Qualitative Research in Sport and Exercise, edited by Brett Smith and

Janghorban, Roksana, Robab Latifnejad Roudsari, and Ali Taghipour. 2014. "Skype Interviewing: The New Generation of Online Synchronous Interview in Qualitative Research.” International Journal of Qualitative Studies on Health and Well-Being 9 (1): 24152. https://doi.org/10.3402/qhw.v9.24152.

637 Kitzinger, Jenny. 1995. “Qualitative Research: Introducing Focus Groups.” Bmj 311 (7000): 638 299. https://doi.org/10.1136/bmj.311.7000.299.

639 Krane, V., and S. M. Baird. 2005. "Using Ethnography in Applied Sport Psychology.” 
Maitland, A., L. A. Hills, and D. J. Rhind. 2015. "Organisational Culture in Sport - A Systematic Review." Sport Management Review 18 (4): 501-16. https://doi.org/10.1016/j.smr.2014.11.004.

Mannion, R, and H Davies. 2016. "Culture in Health Care Organizations.” In The Oxford Handbook of Health Care Management, edited by Ewan Ferlie, Kathleen Montgomery, and Anne Reff Pedersen, First Edit, 98-116. Oxford, UK: Oxford University Press. https://doi.org/10.1093/oxfordhb/9780198705109.001.0001.

Martin, Joanne. 2002. Organizational Culture: Mapping the Terrain. Thousand Oaks

Meyerson, Debra, and Joanne Martin. 1987. "Cultural Change: An Integration of Three Different Views.” Journal of Management Studies 24 (6): 623-47.

Mountjoy, Margo. 2019. “'Only by Speaking out Can We Create Lasting Change’: What Can We Learn from the Dr Larry Nassar Tragedy?” British Journal of Sports Medicine 53 (1): 57-60. https://doi.org/10.1136/bjsports-2018-099403.

Phelps, Annamarie, Jude Kelly, Stuart Lancaster, John Mehrzad, and Annie Panter. 2017. "Report of the Independent Review Panel Into the Climate and Culture of the World Class Programme in British Cycling.” http://www.sportsthinktank.com/uploads/cycling-independent-review.pdf.

Redman-MacLaren, Michelle, and Jane Mills. 2015. "Transformational Grounded Theory: Theory, Voice, and Action.” International Journal of Qualitative Methods 14 (3): 1-12. https://doi.org/10.1177/160940691501400301.

662 Rosa, Edinete M., and Jonathan Tudge. 2013. "Urie Bronfenbrenner's Theory of Human 663 Development: Its Evolution From Ecology to Bioecology." Journal of Family Theory 
664

665

666

667

668

669

670

671

672

673

674

675

676

677

678

679

680

681

682

683

684

685

686

687

\& Review 5 (December): 243-58. https://doi.org/10.1111/jftr.12022.

Ryba, Tatiana V., Natalia Stambulova, Gangyan Si, and Robert J. Schinke. 2013. "ISSP Position Stand: Culturally Competent Research and Practice in Sport and Exercise Psychology.” International Journal of Sport and Exercise Psychology 11 (2): 123-42. https://doi.org/10.1080/1612197X.2013.779812.

Schein, Edgar H. 1990. "Organizational Culture." American Psychologist 45: 109-19. https://doi.org/10.1037/0003-066X.45.2.109.

Schinke, Robert J., Amy T. Blodgett, Tatiana V. Ryba, San Fu Kao, and Thierry R.F. Middleton. 2018. “Cultural Sport Psychology as a Pathway to Advances in Identity and Settlement Research to Practice." Psychology of Sport and Exercise, no. August (September): 0-1. https://doi.org/10.1016/j.psychsport.2018.09.004.

Schinke, Robert J., and Natalia Stambulova. 2017. "Context-Driven Sport and Exercise Psychology Practice: Widening Our Lens beyond the Athlete." Journal of Sport Psychology in Action 8 (2): 71-75. https://doi.org/10.1080/21520704.2017.1299470.

Skille, Eivind, and Stiliani "Ani”" Chroni. 2018. "Norwegian Sports Federations' Organizational Culture and National Team Success." International Journal of Sport Policy 10 (2): 321-33. https://doi.org/10.1080/19406940.2018.1425733.

Smith, Brett, and Kerry R. McGannon. 2018. "Developing Rigor in Qualitative Research: Problems and Opportunities within Sport and Exercise Psychology." International Review of Sport and Exercise Psychology $11 \quad$ (1): 101-21. https://doi.org/10.1080/1750984X.2017.1317357.

Stambulova, Natalia, and Tatiana V. Ryba. 2013. Athletes' Careers across Cultures. Routledge.

Steen-Johnsen, Kari, and Dag Vidar Hanstad. 2008. "Change and Power in Complex 
688

Democratic Organizations. The Case of Norwegian Elite Sports." European Sport Management Quarterly 8 (2): 123-43. https://doi.org/10.1080/16184740802024393.

Storm, Louise Kamuk, Kristoffer Henriksen, Carsten Hvid Larsen, and Mette Krogh Christensen. 2014. "Influential Relationships as Contexts of Learning and Becoming Elite: Athletes' Retrospective Interpretations.” International Journal of Sports Science and Coaching 9 (6): 1341-56.

Telseth, Frode, and Vidar Halldorsson. 2019. "The Success Culture of Nordic Football: The Cases of the National Men's Teams of Norway in the 1990s and Iceland in the 2010s." Sport in Society 22 (4): 689-703. https://doi.org/10.1080/17430437.2017.1390928.

The Ethics Centre. 2018. "Australian Cricket - A Matter of Balance." https://www.cricketaustralia.com.au/-

/media/B9F2F708C1A540A08847A4758D02CB99.ashx.

UK Sport. 2004. "UK Sport Statement on Funding." 2004. https://www.uksport.gov.uk/news/2004/11/25/uk-sport-statement-on-funding.

UK Sport. $2019 . \quad$ "Future Investment Strategy." http://www.uksport.gov.uk/news/2019/02/12/ /media/files/future-investment-strategystatement-final.doc.

Wagstaff, Christopher R D, and Suzanna Burton-Wylie. 2018. "Organisational Culture in Sport: A Conceptual, Definitional and Methodological Review." Sport \& Exercise Psychology Review 14 (2): 32-52.

Weed, Mike. 2009. "Research Quality Considerations for Grounded Theory Research in Sport \& Exercise Psychology." Psychology of Sport and Exercise 10 (5): 502-10. https://doi.org/10.1016/j.psychsport.2009.02.007.

Weed, Mike. 2017. "Capturing the Essence of Grounded Theory: The Importance of 
712 Understanding Commonalities and Variants." Qualitative Research in Sport, Exercise

713 and Health 9 (1): 149-56. https://doi.org/10.1080/2159676X.2016.1251701.

714 